\title{
The R\&D of HTR-STAC Program Package: Source Term Analysis Codes for Pebble-Bed High-Temperature Gas-Cooled Reactor
}

\author{
Hongyu Chen $\mathbb{D}^{1,2,3}$ Chuan Li, ${ }^{1,2,3}$ Haoyu Xing, ${ }^{1,2,3}$ and Chao Fang $\mathbb{D}^{1,2,3}$ \\ ${ }^{1}$ Institute of Nuclear and New Energy Technology, Tsinghua University, Beijing 100084, China \\ ${ }^{2}$ Collaborative Innovation Center of Advanced Nuclear Energy Technology, Beijing 100084, China \\ ${ }^{3}$ The Key Laboratory of Advanced Reactor Engineering and Safety, Ministry of Education, Beijing 100084, China \\ Correspondence should be addressed to Chao Fang; fangchao@tsinghua.edu.cn
}

Received 1 September 2018; Revised 11 November 2018; Accepted 18 November 2018; Published 2 December 2018

Academic Editor: Eugenijus Ušpuras

Copyright (C) 2018 Hongyu Chen et al. This is an open access article distributed under the Creative Commons Attribution License, which permits unrestricted use, distribution, and reproduction in any medium, provided the original work is properly cited.

\begin{abstract}
Source term analysis is important in the design and safety analysis of advanced nuclear reactor and also provides a radiation safety analysis basis for Modular High-Temperature Gas-Cooled Reactor (HTR). High-Temperature Gas-Cooled Reactor-Pebble-bed Modules (HTR-PM) design by China is a typical Gen-IV and due to different safety concepts and systems, the implements of source term analysis in light water reactors are not entirely applicable to HTR-PM. To solve this problem, HTR-PM Source Term Analysis Code (HTR-STAC) has been developed and related V\&V has been finished. HTR-STAC consists of five units, including LOOP (Primary Circuit Source Term Analysis Code), NORMAL (Normal Condition Airborne Source Term Analysis Code), ARCC (Accident Release Category Calculation code), CARBON (C-14 Source Term Analysis Code), and TRUM (Tritium Source Term Analysis Code). LOOP and NORMAL may be used as calculating primary circuit coolant radioactivity and the release of airborne radioactivity to the environment under normal operating conditions of HTR-PM, respectively. The code ARCC composed of several source term analysis programs in the different typical accidents scenario, including SGTR (Steam Generator Tube Rupture), LOCA (Loss of Coolant Accident), and the Transient Process, is compiled based on the results given by LOOP and NORMAL. CARBON and TRUM are developed to calculate the productions of C-14 and H-3 through a different mechanism. Furthermore, the V\&V has been performed and show some positive results.
\end{abstract}

\section{Introduction}

Modular High-Temperature Gas-Cooled Reactor (HTR) could fulfill the safety goals of Gen-IV nuclear reactors and its fuel characteristics provide high confidence in the practical elimination of large radioactive release from nuclear power plants. Following the concept of design to safety, the first demonstration project of modular HTR in the world (HTR-PM, High-Temperature Gas-Cooled ReactorPebble-bed Modules) is under construction in Shidao Bay (in Shandong, China) and is planned to operate at the end of 2019 [1, 2]. Although HTR-PM is a kind of advanced reactor with inherent safety, the assessment of radioactivity during the operation, which plays an essential role in the radiation protection, is still important $[3,4]$. Source term analysis may supply a radiation safety analysis basis for HTR and could provide the generation, quantity, release, and radiation hazard of radionuclides in a nuclear power plant under Normal and accident conditions, making the design and safety assessment solid and credible.

With the development of nuclear reactor technology, many source term analysis codes have been developed and broad used. KORIGEN, which is developed at FZK on the basis of the Oak Ridge Isotope Generation and Depletion code ORIGEN is used for radionuclides inventory estimation in the reactor core [5]. The French Institut de Radioprotection et de Sûreté Nucléaire (IRSN) and the German Gesellschaft für Anlagen und Reaktorsicherheit mbH (GRS) have developed a system of calculation codes, Accident Source Term Evaluation Code (ASTEC), to study source term of a hypothetical severe accident in a nuclear light water reactor [6-8]. The Japan Atomic Energy Agency (JAEA) has developed an integrated severe accident analysis code THALES2 and keep extending function via adding modules like KICHR (Kinetics 


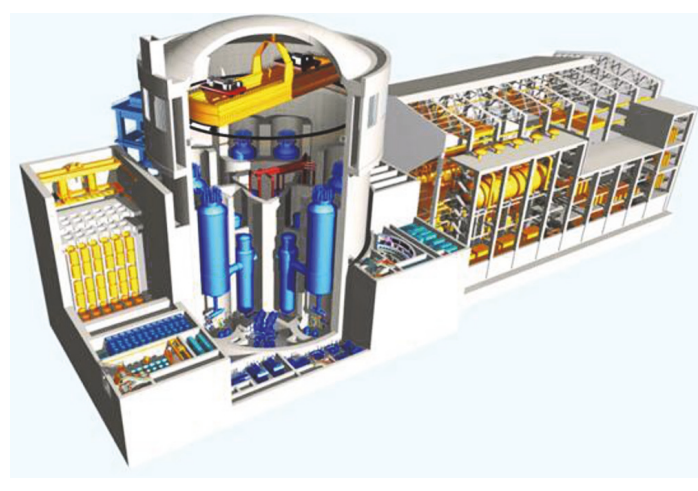

FIgURE 1: Schematic of HTR-PM600.

of Iodine Chemistry in the Containment of Light Water Reactors) [9, 10]. Nevertheless, most source term analysis codes focus on water reactor and are not entirely applicable to HTR.

Source term analysis of HTR-PM has been performed by several commercial software and empirical formula during the design. All results adopt conservation estimations and have been appraised by the National Nuclear Safety Administration (NNSA) of China. At present, commercial software used to study HTR source term only focuses on the radioactivity inventory and release of reactor core while source term of the primary circuit and the release of airborne radioactive materials are not involved. In order to build a more systematic HTR source term analysis program package for the following commercial pebble-bed HTR design, a software package named HTR-STAC (HTR-PM Source Term Analysis Code) is developed. In this article, some prominent features of HTR-STAC are described and the code assessment is also given.

\section{The Features of HTR}

HTR-10 (10 MW High-Temperature Gas-cooled Test Reactor) is the first experimental high-temperature gas-cooled reactor in China, which is designed and constructed in the 1990s, brought to criticality in 2000 , and reached full power operation in 2003 [11] and commercial 600MW High-Temperature Reactor-Pebble-bed Modules (HTR-PM600, Figure 2) will be the next HTR in China (Figure 1). Table 1 shows some main parameters of HTR-10, HTR-PM, and HTR-PM600. It can be seen that HTR-PM and HTR-PM600 share most of the characteristic parameters while some HTR-10s are lower. The lower value is designed to make HTR-10 more controllable to perform tests and experiments. The " $250 \times 2$ " reactor thermal power of HTR-PM represents its two $250 \mathrm{MW}_{\text {th }}$ reactor modules, and HTR-PM600 has six reactor modules. There is just one steam turbine in HTR-PM and the same to HTR-PM600. What is more, the three HTRs have the same coolant, fuel type, and on power refueling model.

HTR-PM is taken, for example, to introduce some most important features of HTR.

As mentioned above, HTR-PM consists of two pebblebed reactor modules coupled with a $210 \mathrm{MW}$ steam turbine.

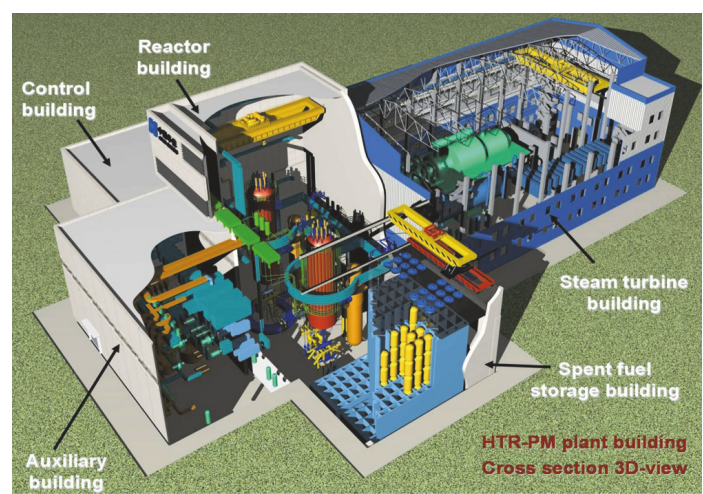

FIGURE 2: HTR-PM plant building cross section 3D view.

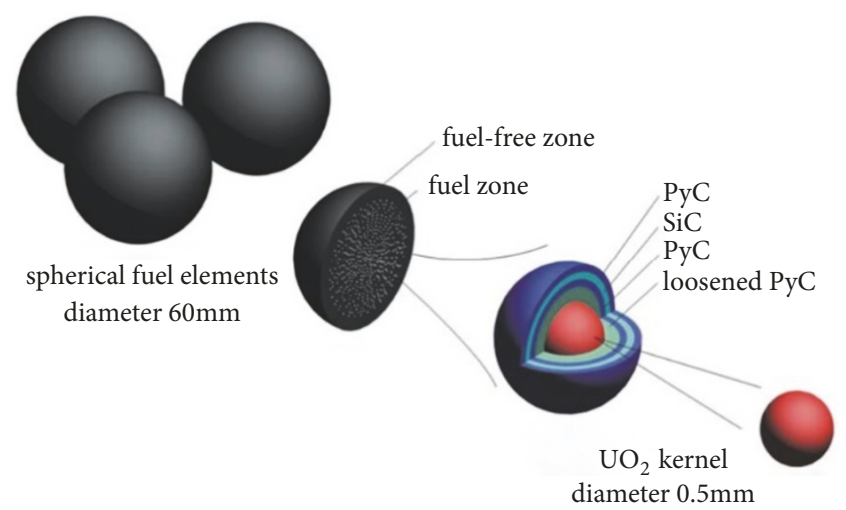

FIgUre 3: The spherical fuel element of HTR-PM.

Each reactor module includes a reactor pressure vessel; graphite, carbon, and metallic reactor internals; a steam generator; and a main helium blower. HTRs use graphite as a moderator as well as structural material and helium as a coolant which could reach $750^{\circ} \mathrm{C}$ at the core outlet. [12]

Spherical fuel element with a diameter of $60 \mathrm{~mm}$ (Figure 3) is used in HTR-PM. Each fuel element contains about 12,000 coated particles which are uniformly embedded in a graphite matrix of $50 \mathrm{~mm}$ in diameter and an outer fuel-free zone of pure graphite surrounds the fuel graphite matrix. A coated fuel particle is composed of an $\mathrm{UO}_{2}$ kernel of $0.5 \mathrm{~mm}$ diameter and three pyrolytic carbon $(\mathrm{PyC})$ layers and one SiC layer (TRISO) [13]. Experimental results show that the spherical fuel element will effectively be retained under $2200^{\circ} \mathrm{C}$, which exceeds the safety limit of $1620^{\circ} \mathrm{C}$ for any operating or accident condition. The heat-resistant property of spherical fuel element ensures core would not melt down.

A unique fuel-discharge system allows the operation mode of HTR-PM to adopt continuous fuel loading and discharging. Fuel elements go through the core by gravity from up and down and are discharged through a fuel extraction pipe at the core bottom. The discharged fuel elements would be measured one by one to check their states of burn-up. A fuel element will be transported into the spent fuel storage tank if it reaches the design burn-up; otherwise, it will pass the core once again. 
TABLE 1: main parameters of HTR-10, HTR-PM, and HTR-PM600.

\begin{tabular}{lccc}
\hline parameter & HTR-10 & HTR-PM & HTR-PM600 \\
\hline Reactor thermal power $(\mathrm{MW})$ & 10 & $250 \times 2$ & $250 \times 6$ \\
Electrical power $(\mathrm{MW})$ & 3 & 200 & 650 \\
coolant & $\mathrm{He}$ & $\mathrm{He}$ & $\mathrm{He}$ \\
Core inlet temperature $\left({ }^{\circ} \mathrm{C}\right)$ & 250 & 250 & 250 \\
Core outlet temperature $\left({ }^{\circ} \mathrm{C}\right)$ & 700 & 750 & 750 \\
Main feed water temperature $\left({ }^{\circ} \mathrm{C}\right)$ & 104 & 205 & 205 \\
Primary helium pressure $(\mathrm{MPa})$ & 3.0 & 7.0 & 7.0 \\
Main steam pressure $(\mathrm{MPa})$ & 4.0 & 14.3 & 13.2 \\
Fuel type & Coated particle spherical fuel & Coated particle spherical fuel & Coated particle spherical fuel \\
Reload model & On power refueling & On power refueling & On power refueling \\
\hline
\end{tabular}

Average core power density of HTR-PM is about 3 $\mathrm{MW} / \mathrm{m}^{3}$ while pressurized water reactor about $100 \mathrm{MW} / \mathrm{m}^{3}$. Lower power density means greater thermal-inertia and a slower rise in core temperature under accident conditions. Besides, two independent shutdown systems are installed in HTR-PM: a control rod system and a small absorber sphere (SAS) system.

HTR-10, HTR-PM, and HTR-PM600 share the same operation model and physical process, resulting in the same source term generation mechanism. Hence, HTR-STAC could be applied to the source term analysis of all these HTRs.

\section{HTR-STAC Description}

The objective of HTR-STAC is to study the accumulation and release of several significant nuclides, such as cesium, strontium, silver, iodide, tritium, etc., in normal and accident condition of pebble-bed HTR. The structure of HTR-STAC is modular and it consists of five units, including LOOP (Primary Circuit Source Term Analysis Code), NORMAL (Normal Condition Airborne Source Term Analysis Code), ARCC (Accident Release Category Calculation code), CARBON (C-14 Source Term Analysis Code), and TRUM (Tritium Source Term Analysis Code) (Figure 4). Each unit can be run independently for separate tests or coupled to take the overall evaluation.

The programming language is Python and the code runs on a PC in diverse environments such as Linux and Windows. In addition, a visual interface with parameters input, results display, and output documents download function is being developed (Figure 5).

3.1. LOOP. To estimate the effect of the most serious accident, i.e., the core melt accident, the amount of core radioactivity has been a significant issue for reactors for a long time. Based on the special design, the special spherical fuel element will be perfect under any accidental condition and there is no melt down of the reactor core. However, fission product (FP) still release from fuel elements would transport in the primary circuit via helium cycle. The primary radioactivity could release slowly under norm operating condition and would be a major source of radioactivity release during an accident. Hence, the primary circuit coolant radioactivity under normal operating conditions of HTRs should be studied and LOOP aims to do that.

FPs in helium is mainly generated in two ways: coated fuel particles failure and uranium contamination. It is found that a very small amount of TRISO particles with a defect layer in spherical fuel elements during the fabrication process and the irradiation would also induce few coated fuel particles failure [18]. Uranium contamination mainly exists on the surface of the coating layer and matrix graphite and sometimes also on natural graphite. Furthermore, the continuous reductions of FPs caused by atom decay, helium purification system, and deposition on the primary circuit surface should be considered in the calculation. The dynamic equation of FPs in the primary circuit could be addressed as

$$
\frac{d C_{i}(t)}{d t}=\frac{R_{i}}{V}-\left(\lambda_{i}+\varepsilon_{i} \frac{Q}{V}+\frac{\delta_{i}}{T}+\omega+\sigma_{a i} \phi_{e} \frac{t_{v}}{T}\right) C_{i}(t)
$$

$C_{i}$ : the concentration of nuclide FP i $\left(\mathrm{Bq} \cdot \mathrm{m}^{-3} \mathrm{~s}^{-1}\right)$.

$R_{i}$ : the release rate of FP $i$ from the core fuel element $(\mathrm{Bq} / \mathrm{s})$.

$V$ : the volume of primary circuit air space $\left(\mathrm{m}^{3}\right)$.

$\lambda_{i}$ : the decay constant of FP i $\left(\mathrm{s}^{-1}\right)$.

$Q:$ purification flow of the helium purification system $\left(\mathrm{m}^{3} / \mathrm{s}\right)$.

$\varepsilon_{i}$ : purification efficiency of helium purification system of FP I (\%).

$\delta_{i}$ : the deposition rate of FP i per cycle (\%).

$T$ : the cycle time of primary circuit helium (s). $\omega$ : the leak rate of primary circuit helium $\left(\% \cdot \mathrm{s}^{-1}\right)$.

$\sigma_{a i}$ : neutron absorption cross section of FP i $\left(\mathrm{cm}^{2}\right)$.

$\phi_{e}$ : core average neutron fluence rate $\left(\mathrm{cm}^{-2} \cdot \mathrm{s}^{-1}\right)$.

$t_{v}$ : time for helium to pass through the core per cycle (s).

FP i generated by activation of materials inside the primary circuit are also considered, and the dynamic equation is given by

$$
B_{i}=\frac{\rho A_{O} f_{n} f_{m}}{A} \cdot \sigma \phi
$$




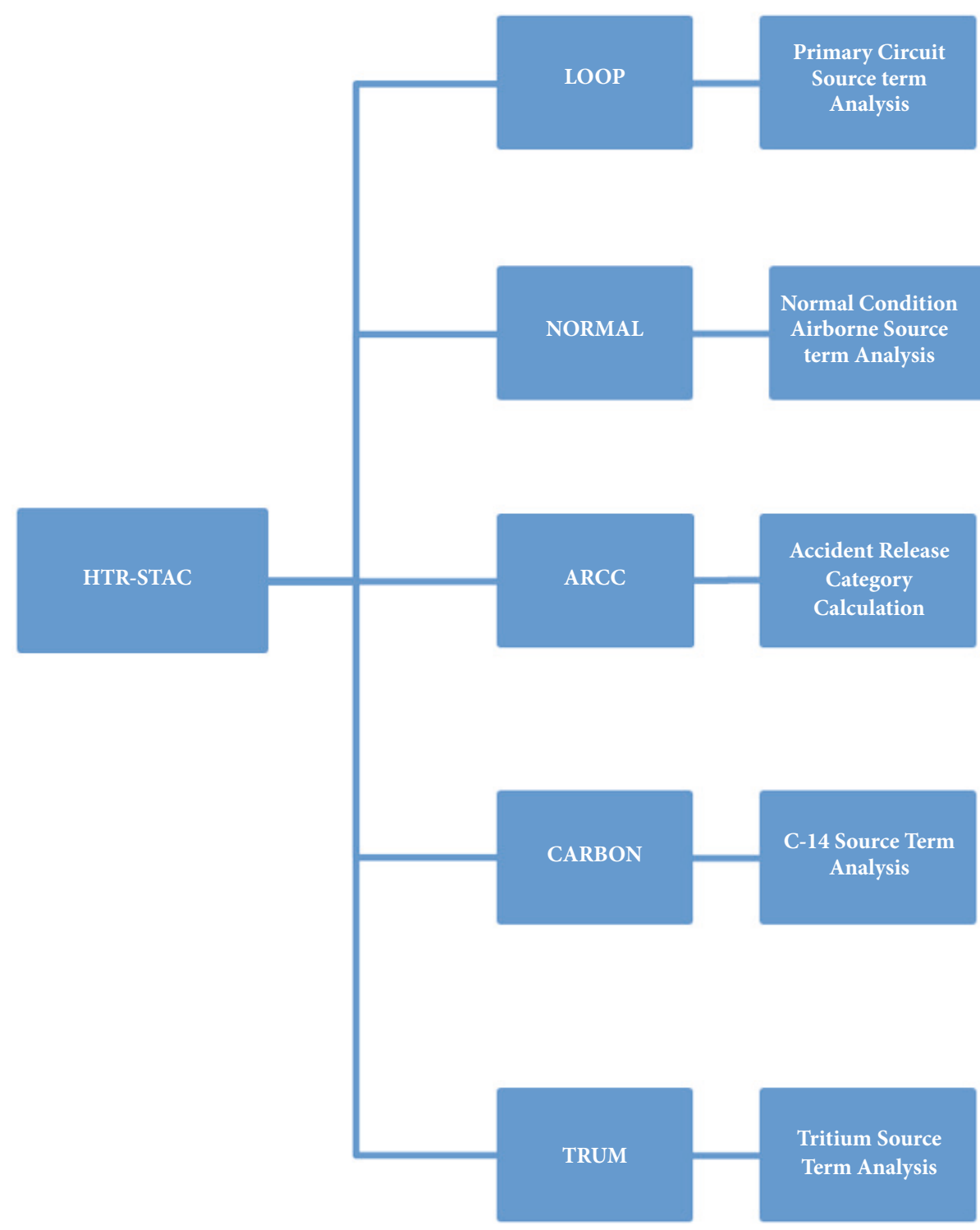

FIgure 4: Construction of HTR-STAC.

$B_{i}$ : the generation rate of FP $\mathrm{i}$ in per unit volume of material (m-3·s-1).

$\rho$ : material density $(\mathrm{g} \cdot \mathrm{cm}-3)$.

$A_{O}$ : Avogadro's constant $\left(\mathrm{mol}^{-1}\right)$.

$f_{n}$ : natural abundance of target nuclide (\%).

$f_{m}$ : the weight percentage of the target element in the material (\%).

$A$ : molar mass of target nuclide $\mathrm{t}\left(\mathrm{g} \cdot \mathrm{mol}^{-1}\right)$.

$\sigma$ : neutron absorption cross section of Ar-40 (cm2).

$\phi$ : neutron fluence rate $(\mathrm{cm}-2 \cdot \mathrm{s}-1)$.

Based on this equation, LOOP calculates several radioactive nuclides amount chosen by the user in primary circuit coolant, i.e., coolant source term analysis under Normal operating conditions.
3.2. NORMAL. During the operation of pebble-bed HTR, the airborne radioactive material is considered to be the main source of radioactive discharge. It is essential to study this issue for safe areas division and radiation level assessment. Therefore, NORMAL has been developed to study the release of airborne radioactive materials to the environment under normal operating conditions.

Six airborne radioactivity sources are considered (taking HTR-PM, as instance, shown in Figure 6) and calculated individually in NORMAL, including

(A) air activation inside the cavity;

(B) leakage of primary coolant;

(C) venting of contaminated He tank;

(D) venting of fuel-discharge system; 


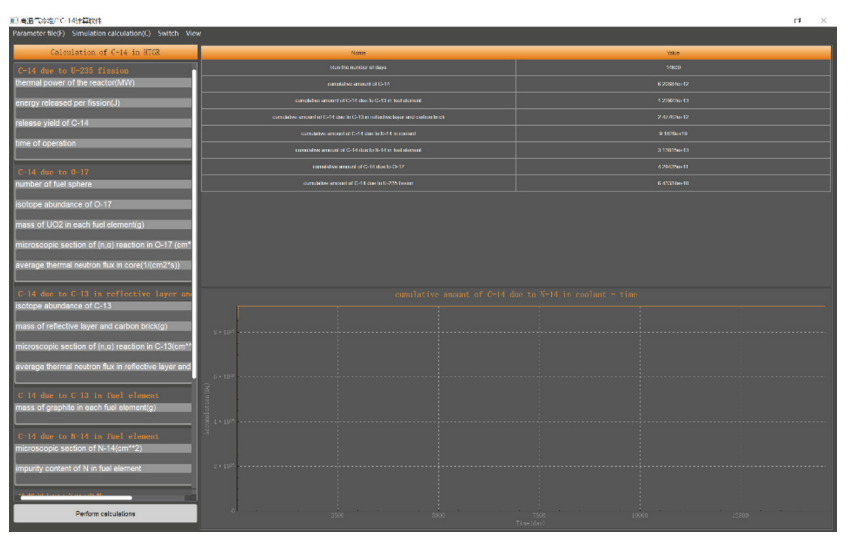

FIGURE 5: HTR-STAC visual interface.

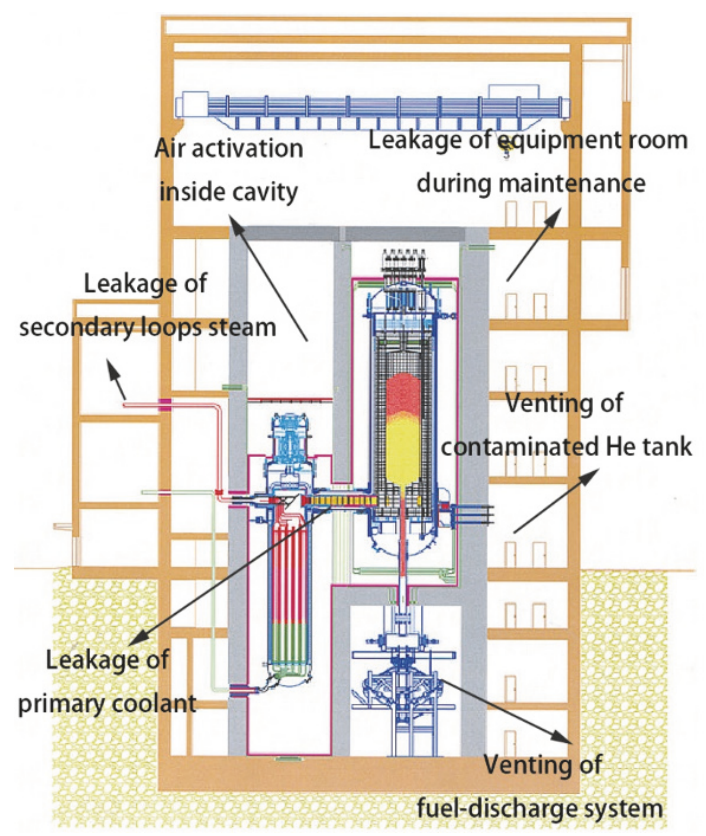

Figure 6: Airborne radioactivity sources of HTR-PM [11].

(E) leakage of secondary loop steam;

(F) leakage of equipment room during maintenance.

A cavity negative pressure air exhausting system has been installed in HTR-PM to discharge cavity air after filtration. However, Ar-41, a radionuclide generated by neutron activation from Ar- 40 , which shares $0.93 \%$ of air, cannot be filtrated and would release to atmosphere through the system at the same time. The dynamic equation is given by

$$
C(t)=\frac{\rho A_{O} f_{n} f_{m}}{A} \cdot \frac{\sigma_{c} \phi}{\lambda+W+\sigma_{a} \phi}
$$

$C(t)$ : the concentration of $\mathrm{Ar}-41$ at time $\mathrm{t}(\mathrm{m}-3)$.

$\rho$ : air density $(\mathrm{g} \cdot \mathrm{cm}-3)$.

$A_{\mathrm{O}}$ : Avogadro's constant (mol-1). $f_{n}$ : natural abundance of Ar-40 (\%).

$f_{m}$ : the weight percentage of element Ar in the air (\%).

A: molar mass of Ar-40 $\left(\mathrm{g} \cdot \mathrm{mol}^{-1}\right)$.

$\lambda$ : decay constant of Ar- $40\left(\mathrm{~s}^{-1}\right)$.

$\sigma_{c}$ : neutron absorption cross section of Ar-40 (cm2).

$\phi$ : cavity average neutron fluence rate $(\mathrm{cm}-2 \cdot \mathrm{s}-1)$.

$W$ : removal constant due to negative pressure $\left(\mathrm{s}^{-1}\right)$.

$\sigma_{a}$ : neutron absorption cross section of Ar-41 $(\mathrm{cm} 2)$.

A little helium leaking from primary coolant and some radioactive gas generated by fuel-discharge system and maintenance of equipment room also release through negative pressure air exhausting system with filtration.

Waste helium in contaminated helium tank is mainly produced in the regeneration of helium purification system. Because of the decline of purification equipment's ability to transform or adsorb impurities, helium purification system needs regeneration after ten days. Desorption of parts of absorbed radioactive nuclides in this process makes them contribute to airborne radioactivity, too.

Due to the activation and penetration of some radioactive materials, the secondary loop steam also has certain radionuclides and they are mainly tritium. The amount of airborne radioactivity leaked from the secondary loop steam is related to the concentration of tritium in the secondary loop and the operating status of the turbine.

NORMAL estimates the six parts' air activation and presents an output result including each part's radioactivity and total evaluation.

3.3. ARCC. LOOP and NORMAL perform normal condition source term analysis while ARCC study accident release category. The calculation results make a great contribution to safety estimation and Emergency Planning Zone division.

SGTR (Steam Generator Tube Rupture), LOCA (Loss of Coolant Accident), and Transient Process are three typical accidents on pebbled bed HTR. They are all considered in ARCC code and could represent most design basic accidents (DBA) in HTR. However, the source term analysis of beyond design basic accidents (BDBA) needs to be proceeded by a different way so they are not included in ARCC.

Generally speaking, there are two release processes in the accident progress. One is transient release and the other is long-term release. ARCC firstly classifies accidents by several input accident parameters and then outputs instant release, long-term release, and a total release, respectively. Input parameters describe the characteristic and states of an accident, including fuel temperature, valve state, filtration efficiency, flooding quantity, etc. The long-term release comes from radioactive fission products in fuel elements caused by the heat up of the core after accidents and it is mainly decided by core temperature. However, instant release varies from accident to accident and should be studied case by case.

3.3.1. SGTR. Steam generator of HTR-PM has 19 heat exchange pipes (Figure 7). The pressure of primary circuit 


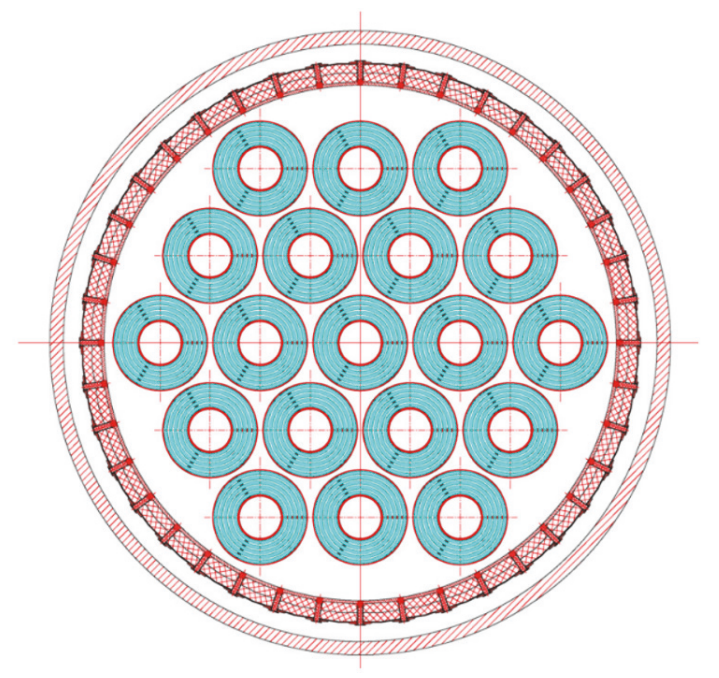

FIGURE 7: Cross section of a steam generator with 19 assemblies [11].

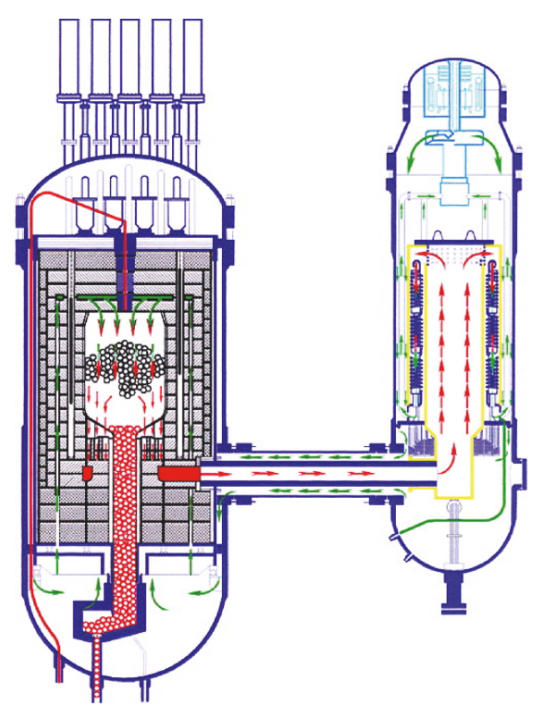

FIgURe 8: Primary circuit of HTR-10 [11].

of HTR-PM is lower than the secondary circuit, so once a break occurs, water and water vapour in the secondary circuit would rapidly flow into the primary circuit and wash out radioactivity deposited on the steam generator and primary circuit. A higher pressure would trigger safety valves by which radioactivity release through. According to the size of the tube break, SGTR falls into three types:

(A) Small break of the heat pipe, represented by the double-end fracture of one heat pipe.

(B) Large break of the heat pipe, represented by the double-end fracture of several heat pipes.

(C) Complete rupture of the generator tube, which means the steam generator heat transfer tube plate ruptures.

Radioactivity instant release in SGTR consists of three parts:
(A) The primary circuit coolant radioactivity during steady operation before the accident which could be studied by LOOP.

(B) The radioactivity deposited on the inner surface of the steam generator washed into the primary coolant.

(C) The radioactivity caused by the reacts between water vapour and matrix graphite or broken fuel element.

3.3.2. LOCA. LOCA of HTRs is the same as water reactors except the coolant is helium instead of water. The highpressure helium with radioactive materials discharged into the containment vessel through a primary circuit break will cause a pressure increase and then trigger rupture discs so that airborne radioactivity would release to the environment.

The accident severity levels of LOCA are decided by the break size of primary circuit tube. Radioactivity instant release in LOCA also consists of three parts:

(A) The primary circuit coolant radioactivity during steady operation before the accident, the same as SGTR.

(B) Desorption of adsorptive radioactivity deposited on the inner surface of the primary circuit.

(C) Desorption of adsorptive radioactivity in helium purification system.

3.3.3. Transient Process. The Transient Process is an accident which causes a turbine trip in addition to SGTR and LOCA. Transient Process also causes a pressure increase and the radioactivity instant release in the Transient Process is the same as LOCA, but release through safety valve instead of break pipe.

3.4. CARBON and TRUM. C-14 and tritium are two special radionuclides in HTR which needed to be studied separately. C-14 exists mainly in the form of carbon dioxide in the environment and could be easily entered into the human body through carbon cycling and a 5730-year half-life makes its influence cannot be ignored. Tritium oxide (HTO, DTO, or T2O) can be inhaled and can combine with organic matter and hard to excrete, resulting in internal irradiation, which is very harmful to the human body, too. C-14 and tritium are generated by two ways: ternary fission and neutron reactions (Tables 2 and 3). CARBON and TRUM study the cumulative quantity and cumulative rate of C-14 and tritium of each reaction in a specified time which can be set by users.

Neutron activation reaction should be calculated by corresponding formula while the amount of $\mathrm{H}-3$ or C-14 generated per unit of time by ternary fission reaction of heavy nuclides can be given by

$$
\frac{d N_{T}^{X}}{d t}=\frac{P}{g} \cdot y(X) \cdot f(X)
$$


TABLE 2: C-14 generated in HTR-PM.

\begin{tabular}{lcc}
\hline Reaction type & Reaction formula & Reaction zone \\
\hline Ternary fission reaction & $\mathrm{U}-235(\mathrm{n}, \mathrm{f}) \mathrm{C}-14$ & fuel elements and matrix graphite \\
\hline \multirow{3}{*}{ Neutron activation reaction } & $\mathrm{N}-14(\mathrm{n}, \mathrm{p}) \mathrm{C}-14$ & coolant and fuel elements \\
& $\mathrm{O}-17(\mathrm{n}, \alpha) \mathrm{C}-14$ & fuel elements and matrix graphite \\
& $\mathrm{C}-13(\mathrm{n}, \gamma) \mathrm{C}-14$ & matrix graphite, graphite reflector and fuel elements \\
\hline
\end{tabular}

TABLE 3: Tritium generated in HTR-PM.

\begin{tabular}{lcc}
\hline Reaction type & $\begin{array}{c}\text { Reaction } \\
\text { formula }\end{array}$ & Reaction zone \\
\hline & $\mathrm{He}-3(\mathrm{n}, \mathrm{p})$ & coolant \\
$\mathrm{H}-3$ & matrix graphite, graphite reflector, and carbon brick \\
Li-6 $(\mathrm{n}, \alpha)$ & matrix graphite, graphite reflector, Boron containing carbon brick, control rod, and \\
absorber ball
\end{tabular}

$g$ : the energy released from each fission reaction $(3.27$ $\times 10-17 \mathrm{MW} \cdot \mathrm{s}$ (each fission).

\section{HTR-STAC Code Assessment}

According to IEEE-1012 and HAF-102 (Quality Assurance for Safety in Nuclear Plants), we conducted the verification and validation of HTR-STAC.

Beijing QunYuan Power Technology Co., Ltd., helped us perform the first verification. They finished the code reading and algorithm analysis and performed several examples to confirm that HTR-STAC could study HTR source term.

We also submitted the code, documentation, and development report to NNSA and they performed the verification of HTR-STAC with the safety analysis report of HTR-PM. NNSA performed static analysis on concept verification, requirements verification, and design verification of HTRSTAC and they performed dynamic analysis on implementation verification and installation and checkout verification of HTR-STAC. They also finished software requirements evaluation, criticality analysis, configuration management assessment, hazard analysis, security analysis, and risk analysis. NNSA confirmed HTR-STAC satisfied the requirements of HTR source term analysis.

And all the subprograms of HTR-STAC have been conducted code validation in combination with other researches or the real operation data. HTR-10 is chosen to obtain operation data. The Institute of Nuclear and New Energy Technology (INET), Tsinghua University, has performed several data-collection campaigns on HTR-10, such as source term experimental analysis of irradiated graphite in the core, sampling of the radioactive graphite dust in the primary loop, and R\&D of helium sampling loop [19-22]. INET also has studied many theoretical calculation approaches like the Monte Carlo method and differential equations to predict the radioactivity in HTR-10 [14, 17, 23, 24].

Validation examples of five modules are described below.
4.1. LOOP. This example is based on real data of HTR-10 (Figure 8). The experiment results, theoretical calculation results, and LOOP running results of radioactive activity of several nuclides in primary circle coolant are showed in Table 4.

The LOOP set temperature at $475^{\circ} \mathrm{C}$, time of $\mathrm{He}$ cycle is $3.13 \mathrm{~s}$, and purification flow is $6100 \mathrm{~cm}^{3} / \mathrm{s}$. The uncertainty of experiment consists of 4 part [14]:

(a) The uncertainty of the instrument count, no more than $5 \%$.

(b) The uncertainty of the counter detection efficiency, no more than $10 \%$.

(c) The uncertainty of delay time between sampling and measurement, no more than $12 \%$.

(d) Other uncertainty, no more than $3 \%$.

It is shown that the activity of $\mathrm{Kr}-85 \mathrm{~m}$ and $\mathrm{Kr}-88$ of LOOP is nearly the same to experiment; the activity of $\mathrm{Kr}-87$ and $\mathrm{Xe}-133$ of LOOP is closer to experiment than theoretical results; the running results of $\mathrm{Xe}-135$ and $\mathrm{Xe}$ $135 \mathrm{~m}$ are not as good as theoretical calculation results to estimate real situation. Due to the fact that reference article has not provided detailed experiment parameters like reactor operating time and coolant temperature, the LOOP results, which are affected by input parameters, may deviate from experimental data. In general, running results of LOOP have good reference value.

4.2. NORMAL. This example is the comparison of design value and NORMAL calculation results of some typical airborne radioactive discharge of HTR-PM under normal operation condition (Table 5). It is shown that the calculation results of $\mathrm{H}-3, \mathrm{C}-14$, and iodine isotopes agree well with design value while the difference of Ar-41 may be due to the different estimation of the cavity space. 
TABLE 4: The comparison of experiment result, theoretical calculation, and HTR-STAC result of several typical nuclides in primary circle coolant of HTR-10.

\begin{tabular}{lccc}
\hline Nuclide & Experiment $(\mathbf{B q} / \mathbf{L})[\mathbf{1 4}]$ & Theoretical calculation $(\mathbf{B q} / \mathbf{L})[\mathbf{1 4}]$ & LOOP $(\mathbf{B q} / \mathbf{L})$ \\
\hline Kr-85m & $3.90 \mathrm{E}+03$ & $2.30 \mathrm{E}+04$ & $4.58 \mathrm{E}+03$ \\
$\mathrm{Kr}-87$ & $1.20 \mathrm{E}+04$ & $5.30 \mathrm{E}+04$ & $8.46 \mathrm{E}+03$ \\
$\mathrm{Kr}-88$ & $1.20 \mathrm{E}+04$ & $5.40 \mathrm{E}+04$ & $1.33 \mathrm{E}+04$ \\
$\mathrm{Xe}-133$ & $1.40 \mathrm{E}+03$ & $3.70 \mathrm{E}+04$ & $1.12 \mathrm{E}+04$ \\
$\mathrm{Xe}-135$ & $2.10 \mathrm{E}+04$ & $4.20 \mathrm{E}+04$ & $7.37 \mathrm{E}+03$ \\
Xe-135m & $1.90 \mathrm{E}+04$ & $2.10 \mathrm{E}+04$ & $2.28 \mathrm{E}+03$ \\
\hline
\end{tabular}

TABLE 5: The comparison of design value and NORMAL calculation results of the airborne radioactive discharge of HTR-PM under normal operation condition.

\begin{tabular}{lcc}
\hline $\begin{array}{l}\text { Airborne } \\
\text { radioactive } \\
\text { material }\end{array}$ & $\begin{array}{c}\text { Design value } \\
\text { (Bq/a) [15] }\end{array}$ & NORMAL (Bq/a) \\
\hline $\mathrm{H}-3$ & $9.75 \mathrm{E}+11$ & $9.76 \mathrm{E}+11$ \\
$\mathrm{C}-14$ & $6.25 \mathrm{E}+11$ & $6.23 \mathrm{E}+11$ \\
Ar-41 & $4.10 \mathrm{E}+12$ & $4.52 \mathrm{E}+12$ \\
Iodine isotopes & $2.01 \mathrm{E}+09$ & $2.00 \mathrm{E}+09$ \\
\hline
\end{tabular}

TABLE 6: The comparison of YuanZhong Liu's research and ARCC calculation results of the LOCA accident.

\begin{tabular}{lcc}
\hline $\begin{array}{l}\text { Radioactivity } \\
\text { releases to the } \\
\text { environment }\end{array}$ & $\begin{array}{c}\text { YuanZhong } \\
\text { Liu's research } \\
[\mathbf{1 6}] \mathbf{( B q})\end{array}$ & $\begin{array}{c}\text { ARCC } \\
(\mathbf{B q})\end{array}$ \\
\hline $\mathrm{Kr}-83 \mathrm{~m}$ & $6.6 \mathrm{E}+08$ & $6.3 \mathrm{E}+08$ \\
$\mathrm{Xe}-135$ & $7.7 \mathrm{E}+09$ & $3.7 \mathrm{E}+9$ \\
$\mathrm{I}-131$ & $4.5 \mathrm{E}+07$ & $2.5 \mathrm{E}+07$ \\
$\mathrm{H}-3$ & $1.2 \mathrm{E}+10$ & $1.1 \mathrm{E}+10$ \\
\hline
\end{tabular}

4.3. ARCC. Due to the safely running of HTR-10, accident experimental data cannot be obtained. Hence, we compared the ARCC results with YuanZhong Liu's research [16] and take a LOCA accident as an example.

It supposes that a $65 \mathrm{~mm}$ diameter pipe break causes the accident, and then the airborne radioactivity releases to the environment. The release of several typical nuclides is shown in Table 6.

It can be seen that ARCC's results are lower that may be due to YuanZhong Liu made some more conservative assumption, such as a higher deposition rate, more graphite dust in He, to simplify model. However, two results are still in the same magnitude, showing ARCC agree with YuanZhong Liu's research.

4.4. CARBON. YuanZhong Liu's research also shows the radioactivity of C-14 in the primary loop and some necessary reactor parameters. The operational thermal power of the reactor is $10 \mathrm{MW}$, primary helium pressure is $3 \mathrm{MPa}$, average burn-up is $80 \mathrm{GWd} / \mathrm{tU}$, and fuel elements are 2700. The corresponding CARBPON input parameters are same with above values and other input parameters take the most
TABLE 7: The comparison of YuanZhong Liu's research and CARBON calculation results of C-14 in the primary loop of HTR-10.

\begin{tabular}{lc}
\hline Source & Value $\left(\mathbf{B q} / \mathbf{m}^{3} \mathbf{S T P}\right)$ \\
\hline YuanZhong Liu's research [16] & $7.4 \mathrm{E}+05$ \\
CARBON & $11.5 \mathrm{E}+05$ \\
\hline
\end{tabular}

TABLE 8: The comparison of experiment result, theoretical calculation, and HTR-STAC result of tritium in the primary loop of HTR10.

\begin{tabular}{lc}
\hline Method & Value $\left(\mathbf{B q} / \mathbf{m}^{3} \mathbf{S T P}\right)$ \\
\hline Experiment [17] & $1.09 \mathrm{E}+04$ \\
Theoretical calculation [17] & $2.31 \mathrm{E}+0.5$ \\
TRUM & $1.28 \mathrm{E}+0.5$ \\
\hline
\end{tabular}

conservative value. AS it is shown in Table 7, CARBON result is about 1.5 times YuanZhong Liu's due to the most conservative assumption.

4.5. TRUM. The comparison of experiment result, theoretical calculation, and TRUM running result of tritium in the primary loop of HTR-10 are showed in Table 8. Most input parameters of TRUM are same as theoretical calculation and as close as possible to the experimental conditions. The operational thermal power of the reactor is $2.9 \mathrm{MW}$, primary helium pressure is $2.1 \mathrm{MPa}$, primary helium flow rate is $1.39 \mathrm{~kg} / \mathrm{h}$, and total He inventory in the primary circuit is $1200{ }_{\text {STP }} \mathrm{m}^{3}$.

The theoretical calculation result is about 20 times higher than experiment data, which shows conservatism for the evaluation of the activity concentration of tritium in the primary loop of HTR-10. The calculation result of HTR-STAC is also conservative and closer to actual data, which indicates that HTR-STAC is valid and more adoptive than previous theoretical calculation. The discrepancy between HTR-STAC data and experimental data may come from the most conservative input parameters, especially the concentration of $\mathrm{He}-3$ in the helium coolant and Li- 6 in the graphite.

\section{Conclusion and Remarks}

HTR-STAC is a compositive Source Term Analysis Code for Pebble-bed HTR, consisting of LOOP, NORMAL, ARCC, CARBON, and TRUM. Each subroutine of HTR-STAC could run independently or unites together. All subprograms are 
performed code validation and the results show that HTRSTAC analysis is closer to experiment than previous theoretical calculation.

Source term analysis of HTR-PM has done before the development of HTR-STAC and the results are reliable. Many algorithms, empirical formulas, and assumptions during the design and safety analysis of HTR-PM are also applied in HTR-STAC. HTRs share the same operation model and physical process so that HTR-STAC could systematically perform source term analysis for most HTRs conveniently and flexibly. In the near future, more pebble-bed HTRs will be design and HTR-STAC will make source term analysis of HTRs more reliable and accurate and would make a great contribution to the design and promotion of pebble-bed HTR.

\section{Data Availability}

The data used to support the findings of this study are available from the corresponding author upon request.

\section{Conflicts of Interest}

The authors declare that they have no conflicts of interest.

\section{Acknowledgments}

This work has been supported by the National S\&T Major Project (Grant no. ZX069).

\section{References}

[1] F. Chao, R. Morris, and F. Li, "Safety Features of High Temperature Gas Cooled Reactor," Science and Technology of Nuclear Installations, vol. 2017, Article ID 9160971, 3 pages, 2017.

[2] Z. Zhang, Y. Dong, and F. Li, "The Shandong Shidao Bay $200 \mathrm{MWe}$ high-temperature gas-cooled reactor pebble-bed module (HTR-PM) demonstration power plant: an engineering and technological innovation," Engineering Journal, vol. 2, no. 1, pp. 112-118, 2016.

[3] M. A. Fütterer, E. D'Agata, and X. Raepsaet, "Is tritium an issue for high temperature reactors?” Nuclear Engineering and Design, vol. 306, pp. 160-169, 2016.

[4] L. Yuanzhong and C. Jianzhu, "Fission product release and its environment impact for normal reactor operations and for relevant accidents," Nuclear Engineering and Design, vol. 218, no. 1-3, pp. 81-90, 2002.

[5] J. L. Muswema, G. B. Ekoko, V. M. Lukanda, J. K.-K. Lobo, E. O. Darko, and E. K. Boafo, "Source term derivation and radiological safety analysis for the TRICO II research reactor in Kinshasa," Nuclear Engineering \& Design, vol. 281, pp. 51-57, 2015.

[6] J.-P. van Dorsselaere, C. Seropian, and P. Chatelard, "The ASTEC integral code for severe accident simulation," Nuclear Technology, vol. 165, no. 3, pp. 293-307, 2009.

[7] P. Chatelard, "ASTEC V2 severe accident integral code main features, current V2.0 modelling status, perspectives," Nuclear Engineering Design, vol. 6, pp. 119-135, 2014.
[8] P. Chatelard, S. Belon, L. Bosland et al., "Main modelling features of the ASTEC V2.1 major version," Annals of Nuclear Energy, vol. 93, pp. 83-93, 2016.

[9] N. Watanabe, "Development of THALES-2, a computer code for coupled thermal-hydraulics and fission product transport analyes for severe accident at LWRs and its application to analysis of fission product revaporization phenomena," British Journal of Cancer, vol. 3, pp. 439-440, 1991.

[10] M. Kiyofumi, "Kiche: A simulation tool for kinetics of iodine chemistry in the containment of light water reactors under severe accident conditions," JAEA-Data/Code 2010-034.

[11] Z. Wu, D. Lin, and D. Zhong, "The design features of the HTR10," Nuclear Engineering and Design, vol. 218, pp. 25-32, 2002.

[12] Z. Zhang, Z. Wu, D. Wang et al., "Current status and technical description of Chinese $2 \times 250 \mathrm{MW}_{t h}$ HTR-PM demonstration plant," Nuclear Engineering and Design, vol. 239, no. 7, pp. 12121219, 2009.

[13] C. Tang, Y. Tang, J. Zhu, Y. Zou, J. Li, and X. Ni, "Design and manufacture of the fuel element for the $10 \mathrm{MW}$ high temperature gas-cooled reactor," Nuclear Engineering and Design, vol. 218, article 91, 2002.

[14] Y. Cao and J.-Z. Cao, "Experiment and analysis of fission product activity in primary-loop of $10 \mathrm{MW}$ high-temperature gas-cooled reactor," Yuanzineng Kexue Jishu/Atomic Energy Science and Technology, vol. 41, no. 5, pp. 555-559, 2007.

[15] J. Ziying, "Comparison of radioactive waste in high temperature gas cooled reactors and pressurized water reactors," Annual Report For China Institute of Atomic Energy, p. 244, 2014.

[16] L. Yuanzhong, "Accident radioactive release and environmental impact for HTR-10 high temperature gas cooled experimental reactor," Radiation Protection, pp. 286-292, 1995.

[17] F. Xie, J. Cao, X. Feng et al., "Study of tritium in the primary loop of HTR-10: experiment and theoretical calculations," Progress in Nuclear Energy, vol. 105, pp. 99-105, 2018.

[18] H. Li, X. Liu, F. Xie, and F. Jia, "Experimental study on the content and distribution of key nuclides in an irradiated graphite sphere of HTR-10," Nuclear Engineering and Design, vol. 323, pp. 39-45, 2017.

[19] X. Feng, "Design and Study of Radioactive Graphite Dust Experimental System in Primary Loop of HTR-10," Atomic Energy Science \& Technology, vol. 04, pp. 744-749, 2015.

[20] X. Feng, "Experimental research on the radioactive dust in the primary loop of HTR-10," Nuclear Engineering \& Design, vol. 324, no. 2017, pp. 372-378, 2017.

[21] X. Liu, X. Huang, F. Xie, F. Jia, X. Feng, and H. Li, "Source term analysis of the irradiated graphite in the core of HTR-10," Science and Technology of Nuclear Installations, vol. 2017, 2017.

[22] C. Fang, X. Bao, C. Yang, Y. Yang, and J. Cao, "The R\&D of HTGR high temperature helium sampling loop: From HTR-10 to HTR-PM," Nuclear Engineering and Design, vol. 306, pp. 192197, 2016.

[23] H. Jeong and S. H. Chang, "Development of a method of evaluating an inventory of fission products for a pebble bed reactor," Annals of Nuclear Energy, vol. 35, no. 12, pp. 2161-2171, 2008.

[24] Y. Xu, H. Li, F. Xie, J. Cao, and J. Tong, "Source term analysis of tritium in HTR-10," Fusion Science and Technology, vol. 71, no. 4, pp. 671-678, 2017. 

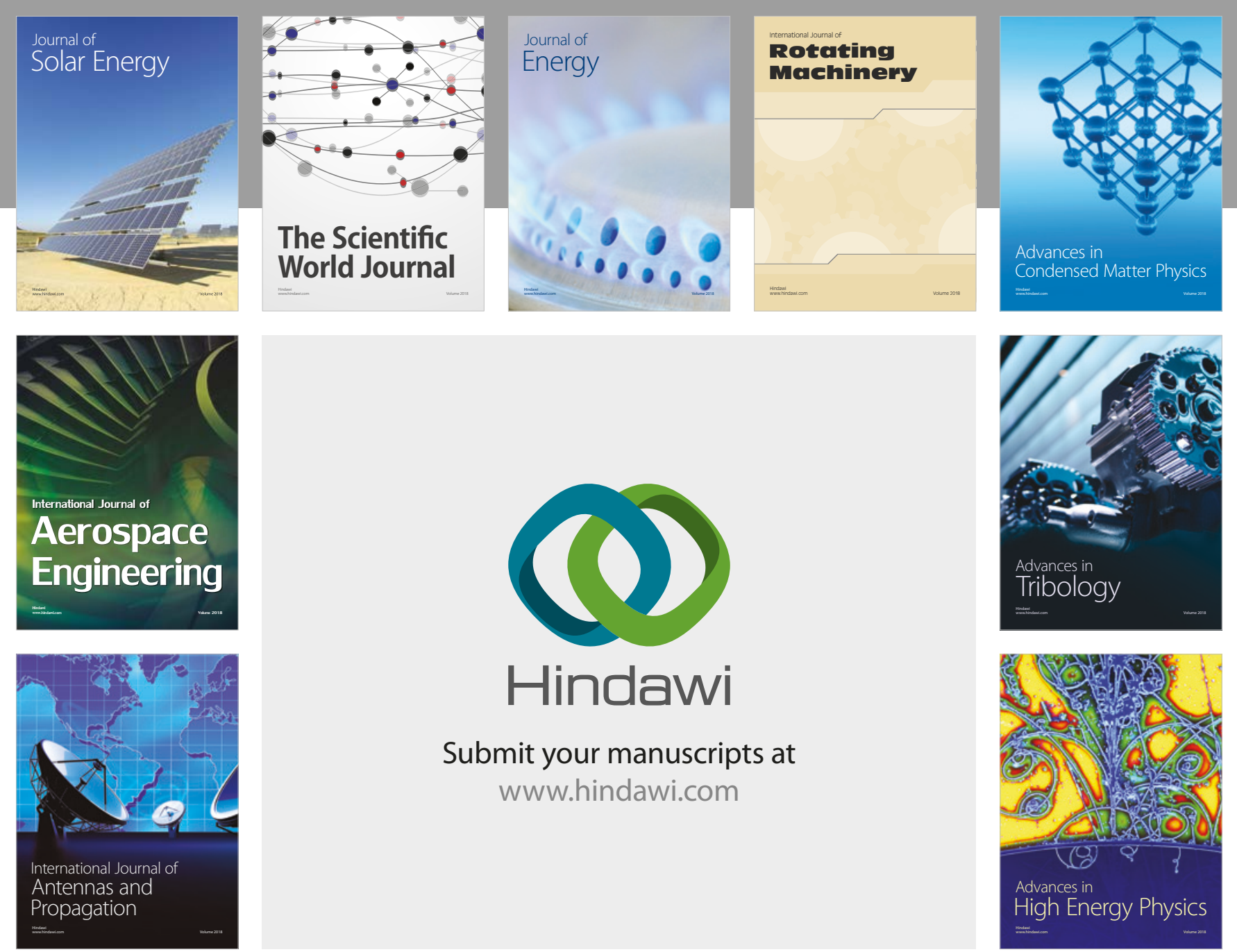

Submit your manuscripts at

www.hindawi.com
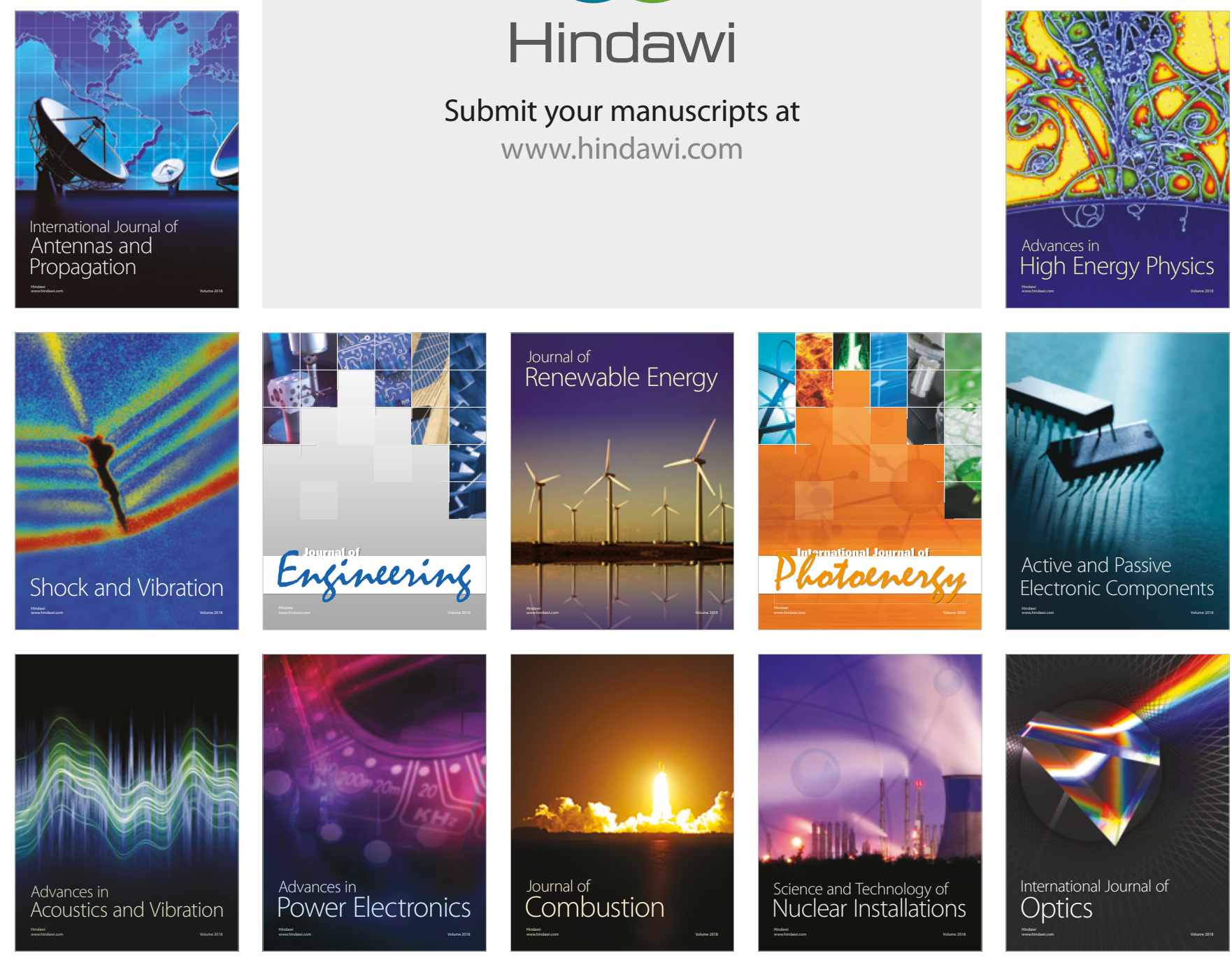